\title{
Rice insect pests and their natural enemies complex in direct seeded and transplanted rice (Oryza sativa) of Chidambaram areas of Cuddalore, India
}

\section{J. Mary Lisha*}

Department of Agricultural Entomology, Institute of Agriculture, Kumulur, Trichy-621712 (Tamil Nadu), India

\section{R.Kanagarajan}

Department of Entomology, Annamalai University, Cuddalolre-608002 (Tamil Nadu), India

\section{S.Vijay}

Department of Agricultural Entomology, Institute of Agriculture, Kumulur, Trichy-621712 (Tamil Nadu), India

\section{Baskaran}

Department of Agricultural Entomology, Institute of Agriculture, Kumulur, Trichy-621712 (Tamil Nadu), India

${ }^{*}$ Corresponding author. Email: lishajoseph28@gmail.com

\section{Article Info}

https://doi.org/10.31018/

jans.v12i3.2316

Received: July 7, 2020

Revised: August 6, 2020

Accepted: August 14, 2020

\section{How to Cite}

Lisha, J. M. et al. (2020). Rice insect pests and their natural enemies complex in direct seeded and transplanted rice (Oryza sativa) of Chidambaram areas of Cuddalore, India. Journal of Applied and Natural Science, 12(3): 349 - 353. https://doi.org/10.31018/ jans.v12i3.2316

\begin{abstract}
Rice is the cereal grain that feeds half the planet. Rice fields are economically important as well as ecologically valuable. Rice fields are one of the biggest ecosystems that can be found in the tropics, including diverse insect pests and their natural enemies. In this view, rice varieties were sown in experimental plots of Faculty of Agriculture, Annamalai University, Chidambaram. The values are found significant at $5 \%$ level. To monitor the pest and natural enemies by using net sweeping and yellow pan trap method was used. The results showed that the maximum number of yellow stem borer was observed in the direct-seeded rice variety of CR Dhan 209 (7.33) and the leaf folder population was maximum in the direct-seeded rice variety of CR Dhan 204 (7.33). The peak population of grasshopper and green leafhopper was recorded in the transplanted rice variety of CR Dhan200 (11.33), CR Dhan 209 (8.00). The values were found significant at 5\% level. The maximum number of Braconidae was observed in direct-seeded rice variety of CR Dhan 205 (3.66), and Ichneumonidae was recorded the highest number of direct-seeded and transplanted rice in the variety of CR Dhan 202 (3.00). The peak population of Trichogrammatidae was recorded in direct-seeded rice of CR Dhan 207 (3.66). The presence of Platygastridae was high in the transplanted rice variety of CR Dhan 201 (8.66), respectively. Among the rice ecosystems, more insect pests and crop damage were noticed in directseeded rice more than the transplanted rice.
\end{abstract}

Keywords: Insect Pests, Net sweeping, Parasitoids, Rice, Yellow Pan Trap

\section{INTRODUCTION}

Rice is one of the important targets of cereal crops to provide food and livelihoods for millions. Rice is mainly grown by direct-seeded rice and transplanted rice. The recent years both the methods of sowing were scarce, expensive and less profitable coupled with excessive use of nitrogenous fertilizers and abuse of agrochemicals have further aggravated the pest menace in transplanted conditions. All these factors demanded a major shift from Transplanted Rice (TR) production to Direct-seeded Rice (DSR) in irrigated and assured or high rainfall areas (Edirisinghe JP, Bambaradeniya CNB, 2006). Among the major insect pests attacking rice are yellow stem borer, leaf folder, green leafhopper, white leafhopper grasshopper and earhead bug. A change from transplanting to direct-seeded rice may affect the status of various pests. The main factors that influence pest status are exposure of very young seedlings to pests, longer plant duration and increasing plant density. The average yield loss in rice have been accounted for $30 \%$ loss in stem borers, while plant hoppers $20 \%$, gall midge $15 \%$, leaf folder $10 \%$ 
and other pests $25 \%$, respectively (Krishnaiah NV, Varma NRG, 2015). Naturally occurring biological control has a potential role to play in the management of rice fields and there is a need to emphasize the impact of indigenous natural enemies as an essential part of the IPM Programme (Ooi PAC, Shephard BM, 2005). Conservation of the natural enemy fauna in-situ for suppressing the pest population seems to be a very good alternative. Abundance and diversity of natural enemies, such as parasitoids and predators, contributes to biological arthropod pest control in different stages of paddy crop (Gangurde S, 2007). A change from transplanting to direct seeding may affect the status of various pests. The main factors that influence pest status are exposure of very young seedlings to pests, longer plant duration in the field and increasing the plant density. This study describes possible changes in pest status and natural enemies in direct seeded and transplanted rice fields. It was felt that a complex and rich web of general and specific insect pests and natural enemies of direct seeded rice (DSR) ecosystem in comparison to the transplanting system needs to be studied.

\section{MATERIALS AND METHODS}

The field experiment was conducted during 2018-19 at Annamalai University Experimental farm, Chidambaram under the direct-seeded and transplanted rice. The varieties- CR Dhan 200, CR Dhan 201, CR Dhan 202, CR Dhan 203, CR Dhan 204, CR Dhan 205, CR Dhan 206, CR Dhan 207 and CR Dhan 209 was sown. The Experimental design was laid out in Randomized Block Design with three replications. The size of the individual plot was $5 \mathrm{~m} \times 4 \mathrm{~m}\left(20 \mathrm{~m}^{2}\right)$ and spacing $20 \times 10 \mathrm{~cm}$.

\section{Collection methods for insect pests}

Net sweeping: A Sweep net was used for the collection of a large number of species in a short period (Noyes and Valentine, 1989). The observations on the occurrence of major insect pests were recorded. One sample consisted of 25 sweeps at each plot of the ecosystem. During each sampling, the insects were collected counted and collected and then transferred to transparent polythene bags which were returned to the laboratory for identification.

Yellow pan trap: This method was used for collecting parasitoids, notably small insects as well as other groups of insects. It works on the principle that many insects were attracted to yellow colour (Noyes JS, 1982). The traps were filled three-fourth with a mild detergent solution to break the surface tension, and the insects were collected then filtered and preserved in $70 \%$ ethyl alcohol.

Statistical analysis: The statistical test ANOVA was also used to check whether there was any significant difference in the collections from different traps. The data on population numbers were transformed into $X+$ 0.5 square root before statistical analysis. The mean individuals caught from the different methods of collection were analyzed by adopting Randomized Block Design (RBD) to find. Critical Difference (CD) values were calculated at a five per cent probability level. All these statistical analyses were done using Microsoft Excel 2016 version and Agres software version 3.01.

\section{RESULTS AND DISCUSSION}

The succession of rice insect pests in different varieties of direct-seeded and transplanted rice through a sweeping net during 2019 is given in Table 1.

Data revealed that the maximum yellow stem borer adult of the population was observed in the Transplanted rice variety of CR Dhan 209 (2.44) followed by direct-seeded rice variety of CR Dhan 209 (2.30), were as the minimum number of population recorded in direct-seeded rice variety of CR Dhan 201(1.00) and CR Dhan 202 (1.13) (Table.1). The statistical analysis showed that the values were significant at $5 \%$ level. In the case of stem borer, direct-seeded rice was damaged more than the transplanted rice, and this might be due to the reason that the direct-seeded rice was in the main field for more duration than the transplanted rice, which might have caused more chances for infestation than the transplanted rice, and it might have coincided with the life cycle of rice stem borer (Ashrith et al. 2016). The population of leaf folder was maximum observed in Transplanted rice, the variety of CR Dhan 204 (2.64) followed by in the Direct-seeded rice variety of CR Dhan 204 (2.33) were as the minimum number of leaf folder was observed in the directseeded rice variety of CR Dhan 201 (1.13). (Girish, 2010) reported that the leaf folder appeared 45 days old rice crop (August 2010) and reached its peak at 105 days old rice crop in October month and highest in drill sown as compared to the transplanted method of cultivation. In the present study, the highest number of grasshopper populations was recorded in the directseeded rice variety transplanted rice variety of $C R$ Dhan204 (3.87) followed by an of CR Dhan 203 (3.65), whereas the lowest number of population was recorded in the transplanted rice variety of CR Dhan 206 (1.41). The peak populations of earhead bug were recorded in direct-seeded rice and transplanted rice the variety of CR Dhan 205 (2.88), whereas the lowest number of population was observed in direct-seeded rice variety of CR Dhan 203 (1.71). The lowest number of green leafhopper population was recorded in directseeded rice variety of CR Dhan 205 (1.27), whereas the maximum number of Green leafhopper was recorded in transplanted rice variety of CR Dhan 204 (2.76). The population of white leafhopper was the 
Lisha, J. M. et al. / J. Appl. \& Nat. Sci. 12(3): 349 - 353 (2020)

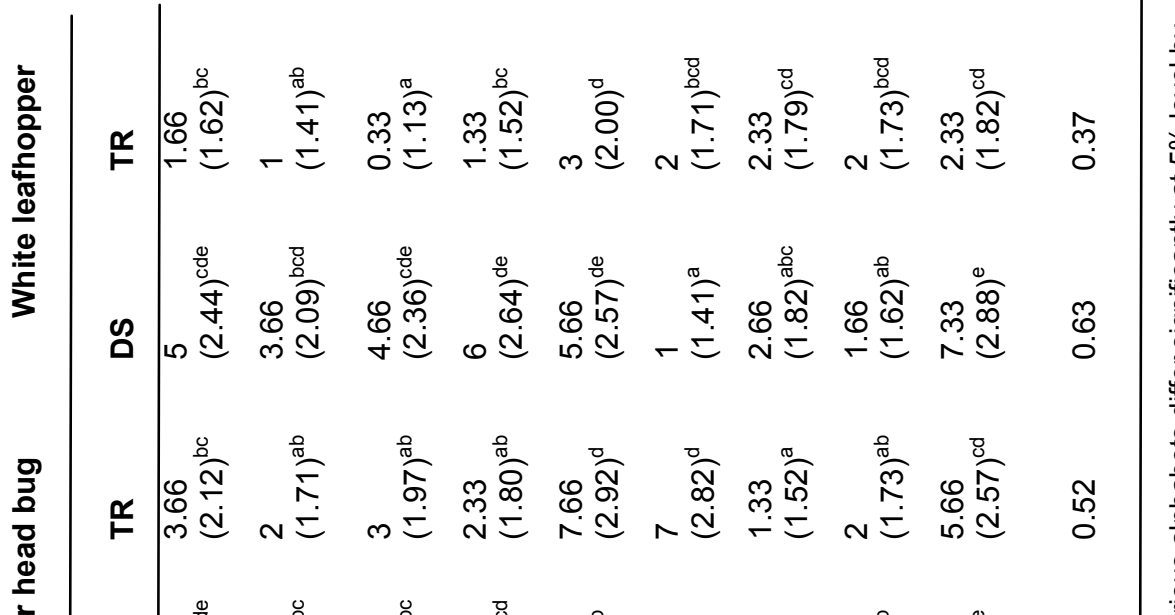

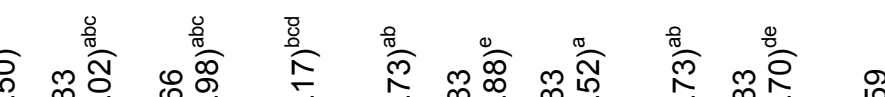
क

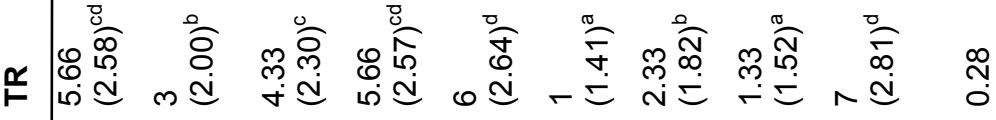

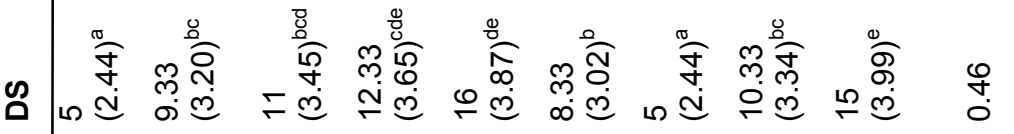

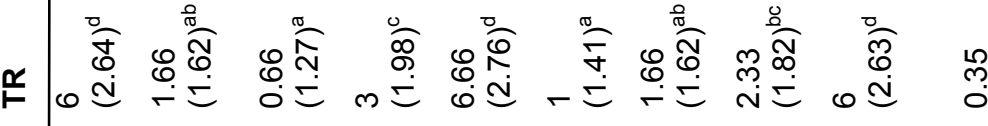

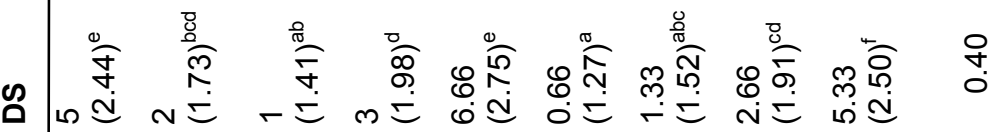

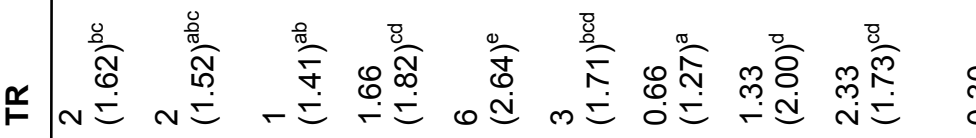
NENE $\mathscr{D}$

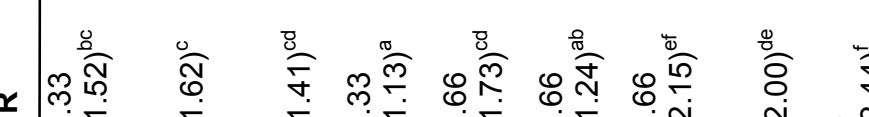

מ

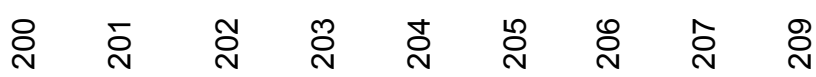




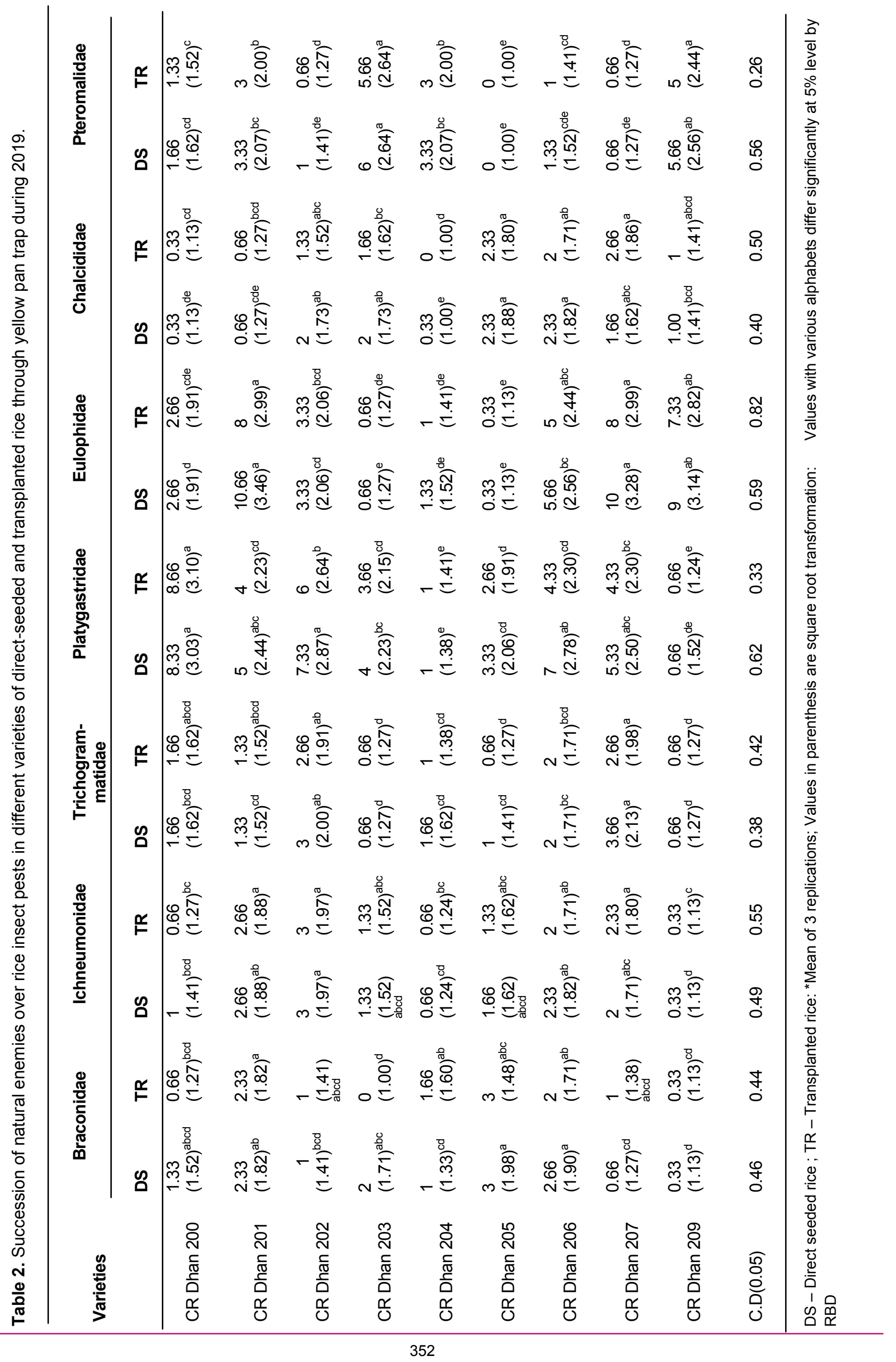


maximum number observed in the direct-seeded rice variety of CR Dhan 209 (2.88), were as the minimum number of white leafhopper was observed in the transplanted rice variety of CR Dhan 203 (1.13), respectively. The succession of natural enemies over rice insect pests in different varieties of direct-seeded and transplanted rice through the yellow pan trap during 20182019 is given in Table 2.

Among the seven families of parasitoids were recorded in direct-seeded and transplanted rice. A maximum number of Braconidae was observed in the directseeded rice variety of CR Dhan 205 (1.98) followed by a direct-seeded rice variety of CR Dhan 206 (1.90). The values were significant at $5 \%$ level, and Ichneumonidae was recorded the highest number of directseeded and transplanted rice in the variety of $C R$ Dhan 202 (1.97). The parasitoid family Chalcididae was collected maximum numbers in transplanted rice variety of CR Dhan 207 (1.86) followed by directseeded rice variety of CR Dhan 206 (1.82) (Table.2). The maximum number of Trichogrammatidae was recorded in direct-seeded rice of CR Dhan 207 (2.13). The presence of Platygastridae was high in the transplanted rice variety of CR Dhan 200 (3.10). Trichogrammatidae and platygastridae parasitized on egg stage of the host. Phenological diversity is an important component of functional diversity, facilitating natural enemy coexistence and diversifying natural enemy effects on pest populations (Vindstad et al., 2011). The presence of Eulophidae was high in the direct-seeded rice variety of CR Dhan 201 (3.46), and the peak population of pteromalidae was the maximum number observed in the direct-seeded rice variety of CR Dhan 209 (2.56) respectively.

\section{Conclusion}

The present study concluded that the yellow stem borer population emerged more from stubbles in transplanted rice as compared to direct-seeded rice. These stubbles leftover in previously cultivated fields served as an alternate host for yellow stem borer infestation. The leaf folder damage was more in direct-seeded rice. The grasshopper and green leafhopper incidence was more in transplanted rice. The population of natural enemies, parasitoids like Braconidae, Ichneumoni- dae, Trichogrammatidae, Eulophidae, Chalcididae, and Pteromalidae was more in direct-seeded rice. A change from transplanting to direct seeding may affect the status of various pests. The main factors that influenced pest status are exposure of very young seedlings to pests, longer plant duration in the field and increasing the plant density. This study describes possible changes in pest status and natural enemies in direct seeded and transplanted rice fields. Among the rice ecosystems, more insect pests and crop damage were noticed in transplanted rice than the directseeded rice ecosystems.

\section{REFERENCES}

1. Ashrith, K. N., Sreenivas, A. G., Guruprasad, G.S., Hanchinal, S. G, Krishnamurthy, D. (2015). Status of insect pests and natural enemies of Direct seeded and transplanted Rice. Mapana Journal of Sciences, 14(4), 11 -29. https://doi.org/10.12723/mjs.35.2

2. Edirisinghe, J. P., and Bambaradeniya, C. N. (2006). Rice fields: an ecosystem rich in biodiversity. Journal of the National Science Foundation of Sri Lanka, 34(2): 57-59.

3. Gangurde, S. (2008). Aboveground arthropod pest and predator diversity in irrigated rice (Oryza sativa L.) production systems of the Philippines. Journal of Tropical Agriculture, 45(1), 1-8.

4. Girish, V. P. (2010). Studies on Insect Pests and Their Predators in Upland Rice Ecosystem (Doctoral dissertation, UAS, Dharwad, India).

5. Krishnaiah, K., and Varma, N. R. G. (2015). Changing insect pest scenario in the rice ecosystem. A national perspective. Directorate of Rice Research Rajendranagar, Hyderabad, 2012, 2-8.

6. Noyes, J. S. (1982). Collecting and preserving chalcid wasps (Hymenoptera: Chalcidoidea). Journal of natural history, 16(3), 315-334. https://doi.org/10.1080/00222938 200770261

7. Noyes, J. S., and Valentine, E. W. (1989). Chalcidoidea (Insecta: Hymenoptera)-Introduction, and review of genera in smaller families. Fauna of New Zealand, (18).

8. Ooi, P. A. C., and Shepard, B. M. (2005). Predators and parasitoids of rice insect pests. Biology and Management of rice insects, 585-612.

9. Vindstad, O. P. L., Hagen, S. B., Jepsen, J. U., Kapari, L., Schott, T., Ims, R. A. (2011). Phenological diversity in the interactions between winter moth (Operophtera brumata) larvae and parasitoid wasps in sub-arctic mountain birch forest. Bulletin of Entomological Research, 101:705-714. 